\title{
Opinions and Controversies in Problem of The So-Called Idiopathic Scoliosis. Information About Etiology, New Classification and New Therapy
}

\author{
T. Karski* \\ Professor Lecturer in Vincent Pol University, Poland
}

Received: 阱: December 19, 2018; Published: 些: January 09, 2019

*Corresponding author: T. Karski, Professor Lecturer in Vincent Pol University, Poland

\section{Abstract}

The biomechanical etiology of the so-called idiopathic scoliosis [adolescent idiopathic scoliosis (AIS)] was the subject of the author's research from 1984 to 2009 in the Pediatric Orthopedic and Rehabilitation Department of Medical University in Lublin, Poland, and in years 2009-2018 in Out-Patient Orthopedic Clinic in Lublin. The basic observation about etiology, new classification and the rules of the new therapy and causal prophylaxis comes from the years 1995-2007.

Spine-Scoliosis (Literature 1-23): The etiology of idiopathic scoliosis was a secret over two thousand years. The biomechanical etiology of scoliosis has been found and described in years 1995 - 2007 (T. Karski, Lublin). The first observations was in program of research of authors in 1984 , during the scholarship stay in Invalid Foundation Hospital in Helsinki, Finland. Over there the first "new clinical symptoms of scoliosis" in the region of pelvis and hips were observed.

Next Observations Were in Years 1984 to 1995 and till 2018 in Lublin. There are following observations: 1/ All children with scoliosis have asymmetrical hip movements and it is one of the symptoms of the "Syndrome of Contracture and Deformities" according to Prof. Hans Mau. In all children with scoliosis adduction of the right hip is limited. This limitation of adduction we observe in straight positing of this joint. Here I explainthis position of examination is equal to "standing" and to "stance phase "during gait. 2 / In some patients with scoliosis, limited internal rotation and extension of the right hip are also observed. 3 / All children with scoliosis have the habit to stand 'at ease' on the right leg. The right hip is more stable and because of this, it is more convenient for permanent standing.

\section{Material}

In the years 1985-2018, 2500 patients mostly in age 5-18 were observed and treated. There was a small group of older patients (60-80 y.), coming with the problem of pain. The older people who were mostly diagnosed with scoliosis, were in the new classification in the second or the third group of the deformity (see next chapterclassification) [1-5].

\section{History of Discoveries}

a) 1995 - The first lecture about the biomechanical etiology of scoliosis was during the Orthopedic Congress in Szeged, Hungary.

b) 1997-Discovery that all children with scoliosis have the habit to stand 'at ease' only on the right leg. The same observation is in adults. Standing on the right leg is permanent and because of this, it is the cause the lumbar left convex curve $[6,7]$. c) 2001-Describing the new classification - two groups and three types of spine deformities: (1) "S"1st epg (epg-etiopathogenesis) scoliosis-connection with "standing on the right leg" and with "gait", (2a) "C" 2nd/A epg scoliosis and (2b) "S" 2nd/B epg scoliosis. Both types (2a) and (2b) are connected with etiological influence of "standing".

d) 2004-Describing in the new classification - the new group of scoliosis. Its property was "stiff spine" only. It is the 3rd type "I" scoliosis [8-11].

e) 2006-Precise information about the "model of movement of hips" and the types of scoliosis in three groups and four types.

f) 2007-Description of additional influences on scoliosis originated in CNS, in children with Minimal Brain Dysfunction (MBD): 
I. Anterior tilt of pelvis,

II. Extension contracture of the trunk even in small children,

III. laxity of joints.

g) In 2007 the author was able to answer the question why blind children do not have scoliosis. Explanation: the children stand on both legs, what is safe and proper, walking without lifting of legs, without possible compensation movements of pelvis and spine-see- $1^{\text {st }}$ and $3^{\text {rd }}$ type of scoliosis.

\section{Classification}

The model of hip movements and the types of scoliosis was presented in Figures 1 \& 2 . When movements of hips, are equal scoliosis never develops. No biomechanical pathological influence acts on the spine. The growth of spine is proper. When movements of hips are asymmetrical, especially if the adduction in straight position of the right hip's joint is limited - there is an input to develop scoliosis in the three groups and four types.

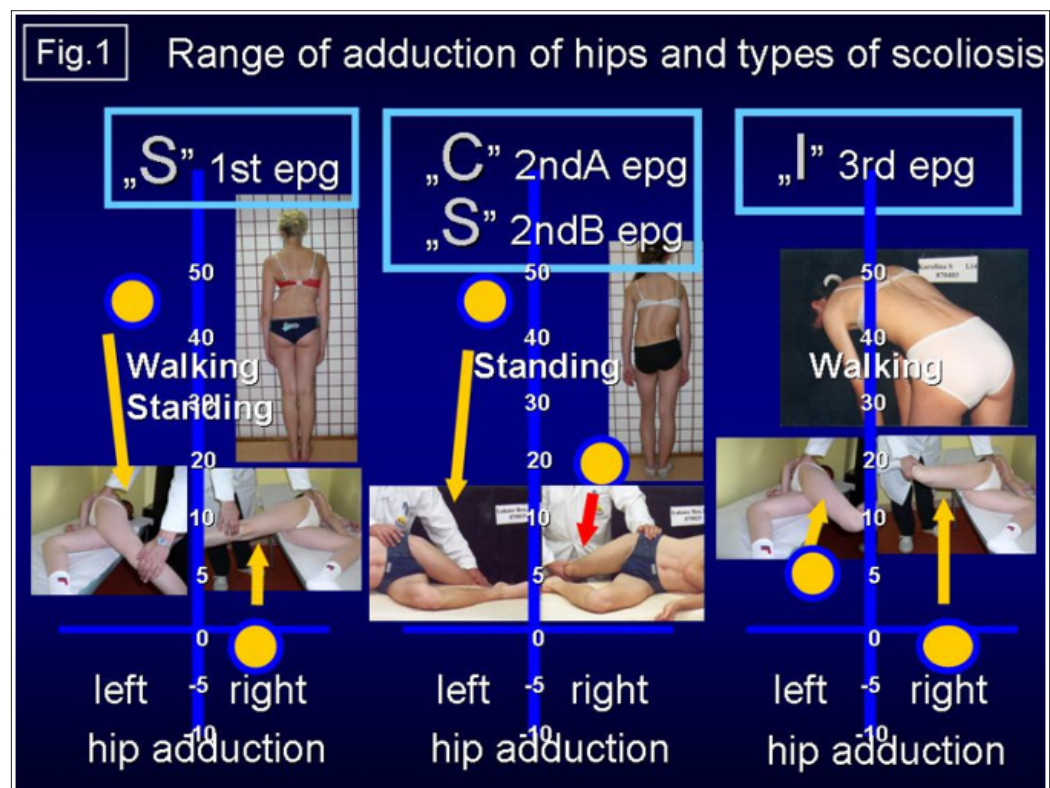

Figure 1: The model of hip movements" and the types of scoliosis.

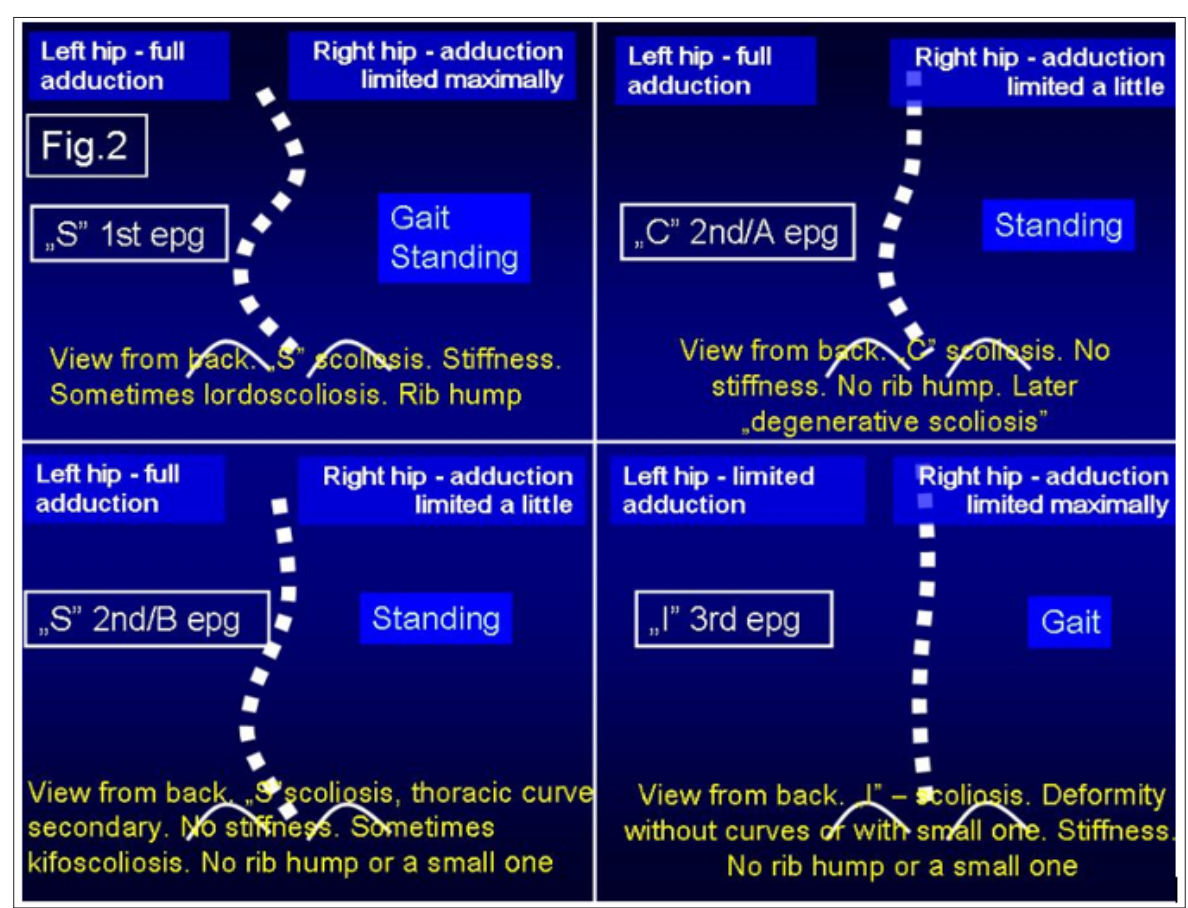

Figure 2: Three groups and four types of scoliosis in new classification. 
a) Scoliosis "S" $1^{\text {st }}$ etiopathological group (epg) - double curve. Stiff spine (3D). Rib hump on the right side of the thorax. Connection with gait and standing at ease' on the right leg $[12,13,15]$.

b) (2a) Scoliosis "C" $2^{\text {nd }} / A$ epg-one curve-lumbar left convex. Spine flexible (1D or 2D). Connection with standing ,at ease' on the right leg only.

c) (2b) Scoliosis "S" $2^{\text {nd }} / \mathrm{B}$ epg-two curves, (2D or 3D). Connection with standing 'at ease' on right leg and additionally with laxity of joints and /or harmful previous exercises. In these two types of scoliosis - $2^{\text {nd }} / \mathrm{A}$ and $2^{\text {nd }} / \mathrm{B}$ - the spine is flexible $[14,16]$.

d) Scoliosis "I" $3^{\text {rd }}$ epg. Deformity has the form of a stiff spine, (2D or 3D). No curves or small ones. The cause is gait only. Such "spine deformity" was till 2004 never classified as "scoliosis".

Information about possibility of causal prophylaxis and new treatment of scoliosis. The principles of the new treatment for all patients are the following

a) No more standing "at ease" on the right leg,

b) Sitting in a relaxed position,

c) Sleeping in embryo position,

d) Stretching and bending exercises are especially important for the spine. The main aim is to achieve by physiotherapy methods, the symmetry of movements of both hips, symmetry of position of pelvis, to remove the anterior tilt of pelvis and to receive full-flexion, deviation and rotation of the spine. The prophylactic exercises should be introduced at the age of 5-6.

e) Flexion exercises for the spine-to the front, to the left, to the right. Here I would like to mention, such exercises for the first time have been recommended in Poland by Prof. Stefan Malawski. His therapy was profitable, however the etiology has not been found at that time $[17,18]$.

f) Sport arts like karate, taekwondo, aikido, kung fu, yoga and other similar are especially profitable.

g) It is especially important to receive the full movement of the right hip as the new, important aim of physiotherapy. To this aim-stretching exercises should be done permanently, every dayuntil the full range of movement of right hip and spine will be achieved. In the therapy of "back pains syndromes" in adult patients it is important not to stand on the right leg-because such standing enlarges the "degenerative scoliosis".

\section{Discussion and Comments to the New Knowledge About Scoliosis}

First, my lectures about biomechanical etiology of scoliosis were given abroad-in Hungary, then in Germany, England, Italy, Spain, during IRSSD Meetings, during SICOT congresses (19952018). On the contrary in my country, in two Orthopedic Congresses in Poland-the new knowledge about scoliosis was not admitted. In the period of ten years (1995 till 2005) my publications were being blocked $[19,20]$. I could publish only abroad-in Germany, Hungary, Czech Republic, USA, Canada. My first publication was in Germany in 1996. The first publication in English was in material of International Research Society for Spinals Deformity (IRSSD) Meeting in Athens in 2002. Till now, in Poland the therapy of children with scoliosis, in many orthopedic and rehabilitation centers has been incorrect and wrong. Very often, even in last years, I am asked by parents to consult patients with "iatrogenic huge deformity" after improper therapy. "The causal prophylaxis of scoliosis" in Poland has not been introduced, what is possible and very simple Some years ago during discussion about scoliosis, Prof. John Sevastik from Stockholm told me (citizen after Hippocrates-460-380): "There are in fact two things: science and opinion. The former begets knowledge, the latter ignorance".

The problem of scoliosis in the world, and also in Poland, has been "ignorance" till now. Here I present the letter from Professor Hans Mau (2003)-about the "status of knowledge about etiology of scoliosis" [21,22] and about "proper line of research on scoliosis in Lublin" (Figure 3a \& 3b).

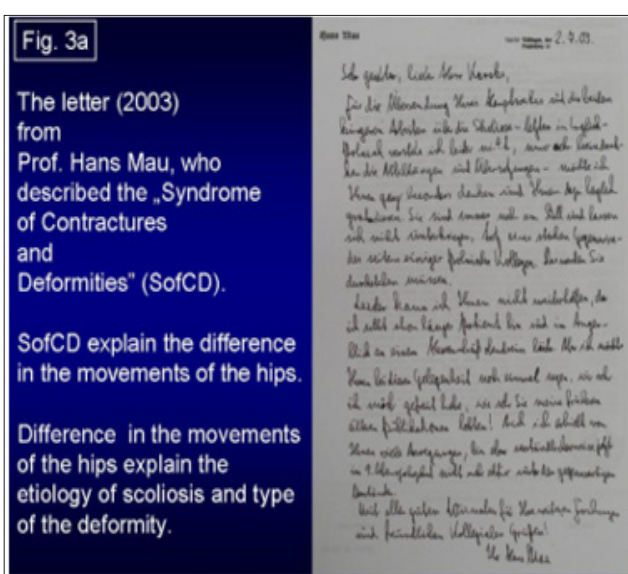

(a)

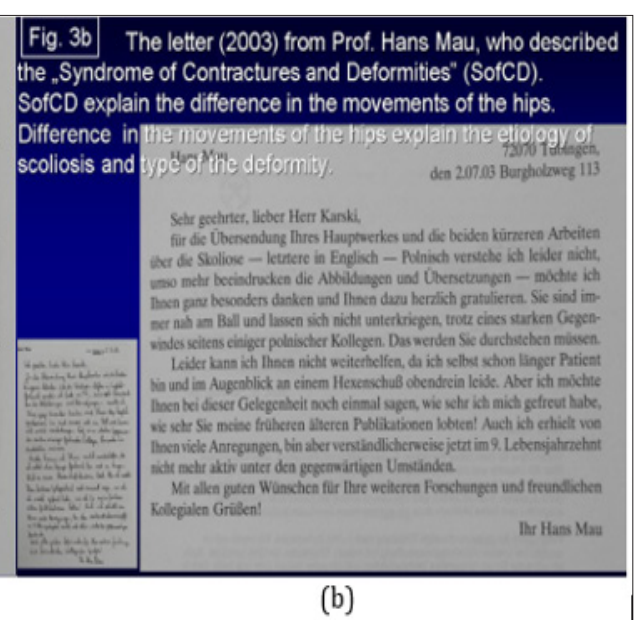

(b)

Figure 3: Letter from Prof. Hans Mau - 2.07.2003. 


\section{Conclusion}

a) In all years of observations (T Karski 1984-2018), it was confirmed the biomechanical etiology of the so-called idiopathic scoliosis.

b) Development of scoliosis and type of spine deformity is connected with pathological "model of hips movements" (T Karski) and function-"standing 'at ease' on the right leg" and "walking".

c) The restricted range of movements in the right hip is connected with the "Syndrome of Contractures and Deformities" according Prof. Hans Mau.

d) Every type of scoliosis starts to develop at the age of 2-3.

e) There are three groups and four types of scoliosis:

I. "S" scoliosis $1^{\text {st }}$ epg, 3D. Causative influence: standing and gait,

II. “C” scoliosis 2 $2^{\text {nd }} /$ A epg, 1D. Causative influence: standing.

III. "S" scoliosis $2^{\text {nd }} / \mathrm{B}$ epg, 1D or 2D. Causative influence: standing, plus, - laxity of joints and/or incorrect exercises in previous therapy,

IV. "I" scoliosis $3^{\text {rd }}$ epg, 2D or 3D. Clinically only stiffness of the spine. Causative influence: gait. The clinical symptom of this deformity is - sport problems in young age and "permanent pain" in adults.

f) The proper therapy of scoliosis-are only stretching exercises to receive full movement of right hip, proper position of pelvis and full movement of spine.

g) The causal prophylaxis of scoliosis is possible and should be introduced in every country.

h) The rules in prophylaxis-are-standing 'at ease' on the left leg, sitting relax, sleeping in embryo position, active participation in sport - especially in karate, taekwondo, aikido and other similarly.

\section{Acknowledgement}

I would like to express my many thanks to Honorata Menet for correction of the article.

\section{References}

1. Burwell G, Dangerfield PH, Lowe T, Margulies J (2000) Etiology of Adolescent Idiopathic Scoliosis: Current Trends and Relevance to New Treatment Approaches 14(2).

2. Green NE, Griffin PP (1982) Hip dysplasia associated with abduction contracture of the contralateral hip. J Bone Joint Surg Am 63(9): 12731281.

3. Hensinger RN (1979) Congenital dislocation of the hip. Clinical Symp.
4. Howorth B (1977) The etiology of the congenital dislocation of the hip Clin Orthop.

5. Karski T (2002) Etiology of the so-called "idiopathic scoliosis". Biomechanical explanation of spine deformity. Two 272 groups of development of scoliosis. New rehabilitation treatment. Possibility of prophylactics, Studies in 273 Technology and Informatics, Research into Spinal Deformities 91(4): 37-46.

6. Karski T, Kalakucki J, Karski J (2006) Syndrome of contractures (according to Mau) with the abduction contracture of the right hip as causative factor for development of the so-called idiopathic scoliosis. Stud Health Technol Inform 123: 34-39.

7. Karski T (2010) Explanation of biomechanical etiology of the so-called idiopathic scoliosis (1995- 2007). New 276 clinical and radiological classification in Pohybove Ustroji 17: 26- 42.

8. Karski Tomasz (2010) Factores biomechanicos en la etiologia de las escoliosis dinominadas idiopaticas. Nueva 282 clasificacion. Nuevos test clinicos y nueavo tratamento conservador y profilaxis 39 (2): 13: 143.

9. Karski Tomasz (2010) Biomechanical Etiology of the So-called Idiopathic Scoliosis (1995-2007). New Classification: 285 Three Groups, Four Subtypes. Connection with Syndrome of Contractures, Pan Arab. J Orth Trauma 14(2): 286

10. Karski Tomasz (2013) Biomechanical Etiology of the So-called Idiopathic Scoliosis (1995 - 2007). Three Groups and 288 Four Types in the New Classification. Journal of Novel Physiotherapies, OMICS Publishing Group pp. 289-290.

11. Karski Jacek, Tomasz Karski (2013) So-Called Idiopathic Scoliosis. Diagnosis. Tests Examples of Children Incorrect 291 Treated. New Therapy by Stretching Exercises and Results. Journal of Novel Physiotherapies, OMICS Publishing 292 Group, pp. 293.

12. Karski Tomasz, Karski Jacek (2015) Syndrome of Contractures and Deformities" according to Prof. Hans Mau as Primary Cause of Hip, Neck, Shank and Spine Deformities in Babies, Youth and Adults American Research. Journal of Medicine and Surgery 1(2).

13. Tomasz Karski, Jacek Karski, Bóle krzyża (2016) problem neurologiczno - ortopedyczny. Objawy. Przyczyny. Leczenie. Back pain - neurologyorthopedic problems. Clinic, causes, therapy and prophylaxis. Postępy Neurologii Praktycznej p. 9-16.

14. Karski Jacek, Karski Tomasz (2016) Imperfect hips as a Problem at an Older Age. Early and Late Prophylactic Management before Arthrosis. Jacobs Journal of Physiotherapy and Exercises 1(2).

15. Mau H (1979) Zur Ätiopathogenese von Skoliose, Hüftdysplasie und Schiefhals im Säuglinsalter. Zeitschrift f. 294 Orthop 5: 601-605.

16. Mau H (1982) Die Atiopatogenese der Skoliose, Bücherei des Orthopäden, Band 33, Enke Verlag Stuttgart pp. 1-296.

17. Mau Hans-personal information and letter.

18. Normelly H (1985) Asymmetric rib growth as an aetiological factor in idiopathic scoliosis in adolescent girls, 298 Stockholm 1: 103-299.

19. Stokes IAF (1999) Studies in Technology and Informatics, Research into Spinal Deformities 2, IOS Press, Amsterdam, Berlin, Oxford pp. 1-385.

20. Sevastik J, Diab K (1997) Studies in Technology and Informatics, Research into Spinal Deformities 1, IOS 300 Press, Amsterdam, Berlin, Oxford pp. 1-509.

21. Sevastik John - personal information.

22. http://www.ortopedia.karski.lublin.pl/ 
ISSN: 2574-1241

DOI: 10.26717/BJSTR.2019.12.002326

T Karski. Biomed J Sci \& Tech Res

This work is licensed under Creative Commons Attribution 4.0 License

Submission Link: https://biomedres.us/submit-manuscript.php

$\begin{array}{ll}\text { BIOMEDICAL } & \text { Assets of Publishing with us } \\ \text { RESEARCHES } & \text { Global archiving of articles } \\ \text { - Immediate, unrestricted online access } \\ \text { https://biomedres.us/ }\end{array}$

